\title{
Effects of PWHT on Microstructure and Mechanical Properties of Weld Metals of Ni-Based Superalloy 617 and 263 for Hyper-Supercritical Power Plants
}

\author{
Jeong Kil Kim ${ }^{1}$ Hae Ji Park ${ }^{1}$ Deog Nam Shim
}

Received: 4 June 2016/Revised: 18 July 2016/Published online: 12 October 2016

(c) The Chinese Society for Metals and Springer-Verlag Berlin Heidelberg 2016

\begin{abstract}
It is well known that solid solution-strengthened alloy 617 and $\gamma^{\prime}$ precipitation-strengthened alloy 263 have excellent mechanical properties and corrosion resistance at high temperatures. Hyper-supercritical power plants work at temperatures above $700{ }^{\circ} \mathrm{C}$, and these superalloys are considered candidate materials for steam turbines components of these power plants. In this study, gas tungsten arc weldability of these superalloys was evaluated, and the effects of postweld heat treatment (PWHT) on the microstructural characteristics and the mechanical properties of their weld metals were investigated. Scanning transmission electron microscopy, energy-dispersive spectroscopy and electron probe microanalysis were utilized for the investigation. The experimental results confirmed that these weld metals had different characteristics in microstructure and mechanical properties. PWHT resulted in the precipitation of intergranular carbides, $\gamma^{\prime}$ particles and an increase in tensile strength of these superalloy weld metals. Furthermore, fine $\gamma^{\prime}$ particles, which were not detected in the as-welded metal of alloy 263, were precipitated after PWHT and those particles were the reason for the drastic increase in tensile strength.
\end{abstract}

KEY WORDS: Superalloy; Welding; Precipitation; Segregation

\section{Introduction}

Much research has recently been carried out to improve the power generation efficiency of thermoelectric power plants all over the world. Increasing the temperature of steam used to rotate the steam turbines of these power plants is considered one of the most effective methods [1-4].

Hyper-supercritical (HSC) power plants work at temperatures above $700{ }^{\circ} \mathrm{C}$. High $\mathrm{Cr}$ steels, which have previously been extensively used for main parts such as steam turbine rotors, operating below $700{ }^{\circ} \mathrm{C}$, cannot be applied

Available online at http://link.springer.com/journal/40195

Jeong Kil Kim

jeongkil1.kim@doosan.com

1 Doosan Heavy Industries and Construction, Changwon, Geongnam, Korea to HSC power plants. Therefore, nickel-based superalloys, which are widely used for gas turbine components, are regarded as the main candidate materials for steam turbine rotors, since these materials have excellent mechanical properties and corrosion resistance at high temperature [5-8].

Nickel-based superalloys can be categorized into two types according to their strengthening mechanisms, namely solid solution-strengthened alloys such as alloy 617, and $\gamma^{\prime}$ and/or $\gamma^{\prime \prime}$ precipitation-strengthened alloys such as alloy 263 [9].

Welding Ni-based superalloys, meanwhile, is known to be very difficult because alloying elements such as $\mathrm{Cr}, \mathrm{Ti}$ and $\mathrm{Nb}$, added to enhance various performance aspects of the superalloys, causes harmful precipitations such as carbides as well as cracking in the welds, and the properties of the welds deteriorate [10-12]. It is asserted that important strengthening elements are likely to segregate into the dendrite boundaries in the weld metals and this 
results in intermetallic particles which exhibit a damaging effect on high-temperature performance [13, 14]. And it is well known that segregation of minor alloying element such as $\mathrm{S}, \mathrm{P}$ and $\mathrm{C}$ and liquation induced by $\mathrm{B}$ aggravate hot cracking in the welds $[15,16]$. Some studies have reported that Ni-based superalloy welds could be susceptible to hot cracking due to constitutional liquation between the austenitic matrix and MC carbides and/or Laves phases [17]. And some studies have attributed the hot cracking to residual stress after welding [18, 19]. Post-weld heat treatment (PWHT) is usually applied to modify the aswelded microstructures for improving their properties [13]. Furthermore, many studies have reported that the precipitation-strengthened alloys suffered more property deterioration in their welds than the solid solution-strengthened alloys despite their better initial properties [20-23].

Nevertheless, welding is an essential process for manufacturing the main components for HSC plants [24]. Hence, a good understanding of the relationship between microstructural characteristics and mechanical properties of the superalloy welds is of critical importance in the application of these materials to HSC plants. There is, however, still a lack of studies not only to investigate but also to compare weldability of solid solution-strengthened and $\gamma^{\prime}$ precipitation-strengthened superalloys, and microstructural characteristics and properties of their weld metals at the same time.

In this study, therefore, gas tungsten arc welding (GTAW) was conducted with alloy 617 and alloy 263, and the welded specimens then underwent PWHT. The weldability of these materials and the mechanical properties of their welds were evaluated. Microstructural characteristics of the weld metals were investigated by scanning transmission electron microscopy (STEM), energy-dispersive spectroscopy (EDS) and electron probe microanalysis (EPMA). Particularly, the $\gamma^{\prime}$ precipitation behavior and its effect on the tensile properties of the weld metals were discussed carefully.

\section{Experimental Methodology}

The specimens used in this experiment are 12- and 16-mmthick sheets of solid solution-strengthened alloy 617 and $\gamma^{\prime}$ precipitation-strengthened alloy 263 with around $2 \mathrm{wt} \% \mathrm{Ti}$ addition for $\gamma^{\prime}$ precipitation. These materials were solutiontreated at $1200{ }^{\circ} \mathrm{C}$ and quenched in water. The chemical composition and the microstructures of these alloys are shown in Table 1 and Fig. 1, respectively.

The welding groove and welding position are explained in Fig. 2. GTA welding was carried out using two types of commercial welding consumables for alloy 617 and alloy 263 under the same welding conditions as given in Table 2. The as-welded specimens underwent penetration inspection
Table 1 Chemical compositions of alloy 617 and alloy 263 (wt \%)

\begin{tabular}{llllllllll}
\hline Alloys & $\mathrm{C}$ & $\mathrm{Si}$ & $\mathrm{Mn}$ & $\mathrm{Cr}$ & $\mathrm{Mo}$ & $\mathrm{Al}$ & $\mathrm{Co}$ & $\mathrm{Ti}$ & $\mathrm{Ni}$ \\
\hline Alloy 617 & 0.06 & 0.1 & 0.02 & 22.3 & 8.8 & 1.0 & 11.5 & 0.4 & Bal. \\
Alloy 263 & 0.05 & 0.2 & 0.04 & 19.9 & 5.8 & 0.5 & 20.0 & 2.1 & Bal. \\
\hline
\end{tabular}

and then were heat-treated for $4 \mathrm{~h}$ at $980{ }^{\circ} \mathrm{C}$ for alloy 617 and $810^{\circ} \mathrm{C}$ for alloy 263 according to the heating cycles suggested by the welding consumable manufacturer (Fig. 3).

The specimens were polished up to $1 \mu \mathrm{m}$ surface finish and etched electrochemically using an etchant $10 \mathrm{~g} \mathrm{CrO}_{3}+$ $90 \mathrm{ml} \mathrm{H}_{2} \mathrm{O}$. Microstructural characterization of the specimens was examined through optical microscopy (OM), EPMA and TEM with EDS. Side bending and tensile tests were performed on the as-welded and the heat-treated (PWHTed) welds at $25{ }^{\circ} \mathrm{C}$ to evaluate mechanical properties. Side bending and tensile tests followed ASTM A 370.

\section{Results and Discussion}

Figure 1 shows the microstructure of the solution-treated base metals. In the OM microstructure of alloy 617 , a lot of particles are observed and these particles form band structures across the grains. The fine particles indicated as "A" are Cr-Mo-rich carbides $\left(\mathrm{M}_{23} \mathrm{C}_{6}\right.$ and/or $\left.\mathrm{M}_{6} \mathrm{C}\right)$, and these appear both along the grain boundaries and inside the grains, while the particles " $\mathrm{B}$ " are Ti-rich carbo-nitrides $(\mathrm{M}(\mathrm{C}, \mathrm{N}))$ in the SEM micrograph of alloy $617[25,26]$. Annealing twins are observed in alloy 617 [26]. OM observation on alloy 263 shows that annealing twins and numerous particles are observed, but the particles disperse uniformly instead of gathering in bands unlike in alloy 617 . The number of the particles in alloy 263 seems to be larger than that in alloy 617. The particles in alloy 263 indicated as " $\mathrm{C}$ " and " $\mathrm{D}$ " are also fine $\mathrm{Cr}-\mathrm{Mo}$ carbides and Ti-rich carbo-nitrides, respectively (in the SEM micrograph of alloy 263 in Fig. 1) [27-30].

The chemical compositions of the alloy 617 and the alloy 263 weld metals are listed in Table 3. Ti and Al are essential alloying elements to precipitate $\gamma^{\prime}$ in Ni-based superalloys. Ti concentration is about $2 \mathrm{wt} \%$ and $\mathrm{Al}$ concentration is $0.45 \mathrm{wt} \%$ in the weld metal of $\gamma^{\prime}$ precipitationstrengthened alloy 263. The main element for $\gamma^{\prime}$ precipitation is thought to be titanium, and it is expected that $\gamma^{\prime}$ precipitation would occur in the alloy 263 weld metal with $\mathrm{Ti}+\mathrm{Al}$ of $2.51 \mathrm{wt} \%$. Meanwhile, the total concentration of $\mathrm{Ti}$ and $\mathrm{Al}$ in the 617 weld metal is about $1.66 \mathrm{wt} \%$. It was, therefore, thought that $\gamma^{\prime}$ precipitation could be 


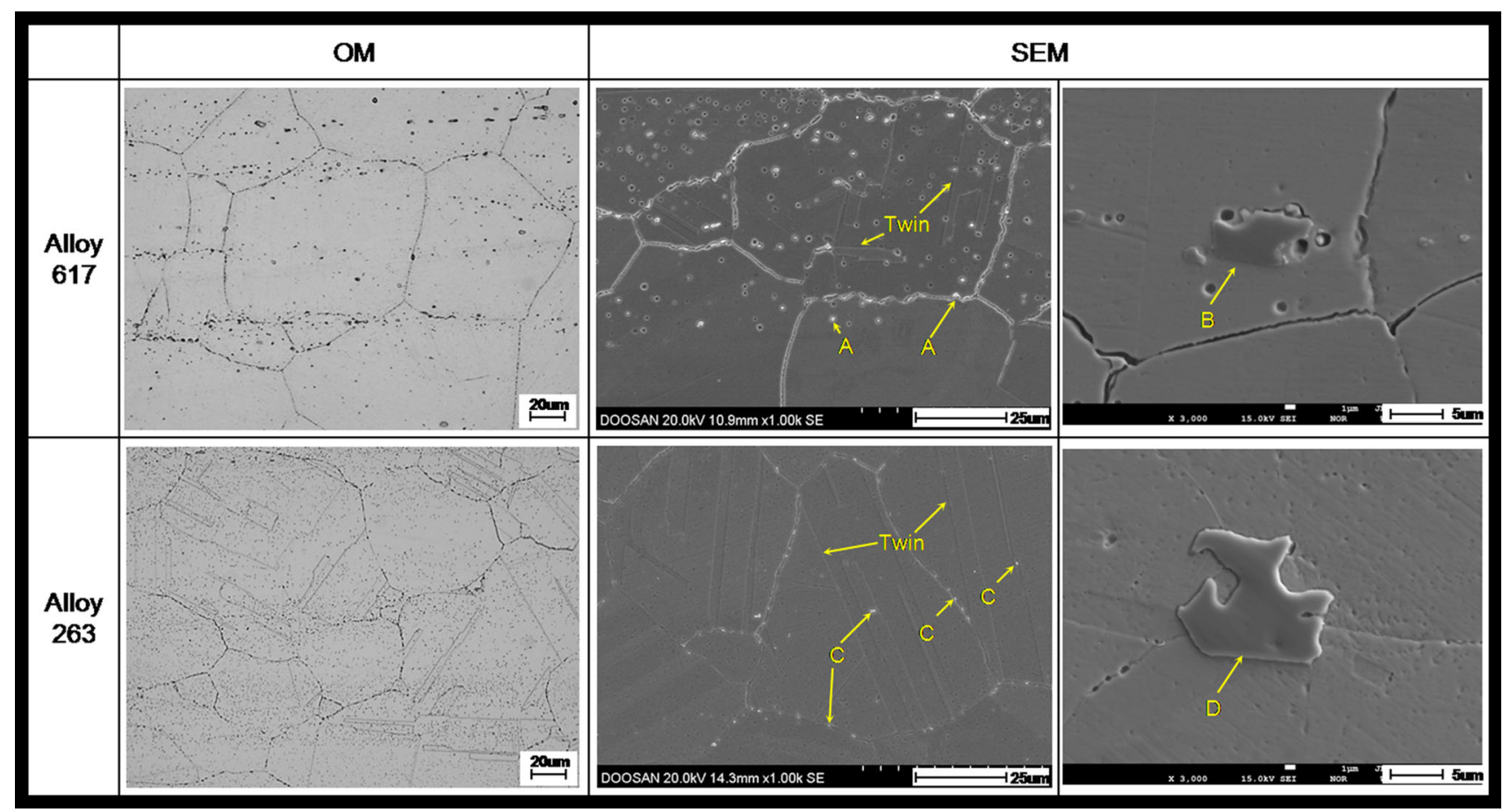

Fig. $1 \mathrm{OM}$ and SEM micrographs of solution-treated alloy 617 and alloy 263

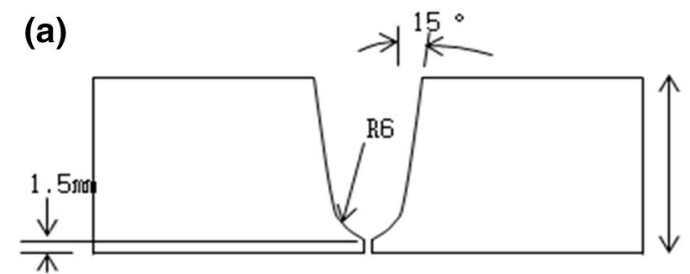

(b)

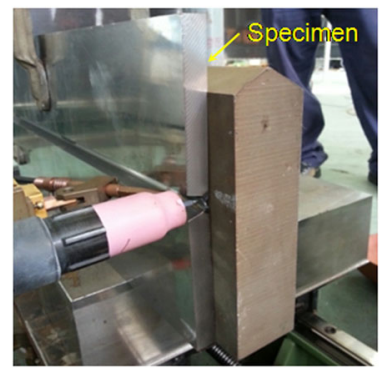

Fig. 2 Schematics of groove a, welding position $\mathbf{b}$

observed in this weld metal, although it was the solid solution-strengthened weld metal. And the $\gamma^{\prime}$ precipitation

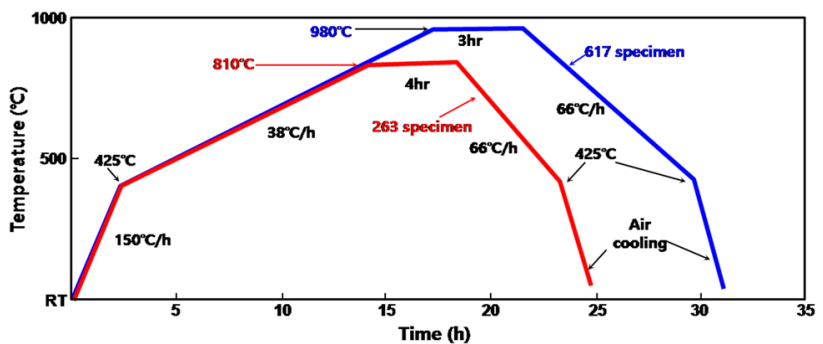

Fig. 3 Heating cycle used in this study

behavior in the 617 weld metal will be discussed by comparison with the 263 weld metal later.

Penetration inspection was conducted on the surface of the top bead of the as-welded specimens and results are presented in Fig. 4. The results show that the specimens are free of defects such as pits and cracks on the surfaces. Spatter also rarely occurred during the actual welding operation. Figure 5 shows the macrostructures of the aswelded specimens of alloy 617 and alloy 263. The results indicate that there are no any evidences of cracks or other

Table 2 Welding conditions

\begin{tabular}{lllllllll}
\hline Process & Position & $\begin{array}{l}\text { Interpass } \\
\text { temp. }\end{array}$ & $\begin{array}{l}\text { Welding } \\
\text { current }\end{array}$ & $\begin{array}{l}\text { Welding } \\
\text { voltage }\end{array}$ & $\begin{array}{l}\text { Traveling } \\
\text { speed }\end{array}$ & Heat input & $\begin{array}{l}\text { Wire feeding } \\
\text { speed }\end{array}$ & $\begin{array}{l}\text { Shielding gas/flow } \\
\text { rate }\end{array}$ \\
\hline GTAW & Horizontal & $30{ }^{\circ} \mathrm{C}$ & $140 \mathrm{~A}$ & $12.5 \mathrm{~V}$ & $10 \mathrm{~cm} / \mathrm{min}$ & $10.5 \mathrm{~kJ} / \mathrm{cm}$ & $80 \mathrm{~cm} / \mathrm{min}$ & $\begin{array}{r}99.99 \% \\
\mathrm{Ar} / 20 \mathrm{~L} / \mathrm{min}\end{array}$ \\
\hline
\end{tabular}


Table 3 Chemical compositions of alloy 617 and alloy 263 weld metals (wt\%)

\begin{tabular}{llllllllll}
\hline Weld metals & $\mathrm{C}$ & $\mathrm{Si}$ & $\mathrm{Mn}$ & $\mathrm{Cr}$ & $\mathrm{Mo}$ & $\mathrm{Al}$ & $\mathrm{Co}$ & $\mathrm{Ti}$ & $\mathrm{Ni}$ \\
\hline Alloy 617 weld metal & 0.07 & 0.11 & 0.12 & 21.67 & 8.82 & 1.3 & 11.42 & 0.36 & Bal. \\
Alloy 263 weld metal & 0.05 & 0.13 & 0.08 & 19.9 & 5.80 & 0.45 & 19.72 & 2.06 & Bal. \\
\hline
\end{tabular}
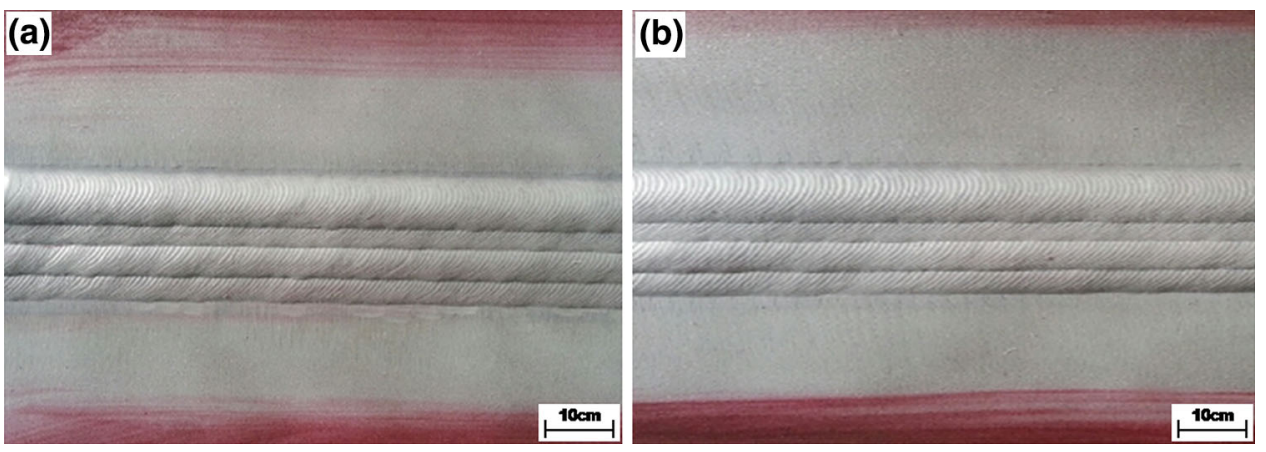

Fig. 4 Penetration inspection results on the surfaces of the as-welded specimens: a alloy 617 weld metal, b alloy 263 weld metal

defects such as porosities and undercuts in the weld metals as well as in the heat-affected zones (HAZ).

In the side bending test for evaluating the formability of the weld metals, the results show that cracking did not occur in any of the welded specimens before and after PWHT as shown in Fig. 6. It can be recognized that weld metals and HAZ of Ni-based superalloys were susceptible to hot cracking and therefore to degrade their formability [15-17, 23, 31, 32]. However, the results stated earlier clarified that these superalloys and the welding consumables in this study have good weldability and that the formability of the welds is excellent.

Figure 7 compares the OM microstructures of the weld metals of alloy 617 before and after PWHT. Dendritic structures are observed clearly in the as-welded specimen. The dendritic structures in the weld metal caused by segregation of solute elements appear at the dendrite boundaries and cores during rapid solidification after welding [13, 14, 33, 34]. The results show that the dendritic structure almost disappeared in the PWHTed specimens; it

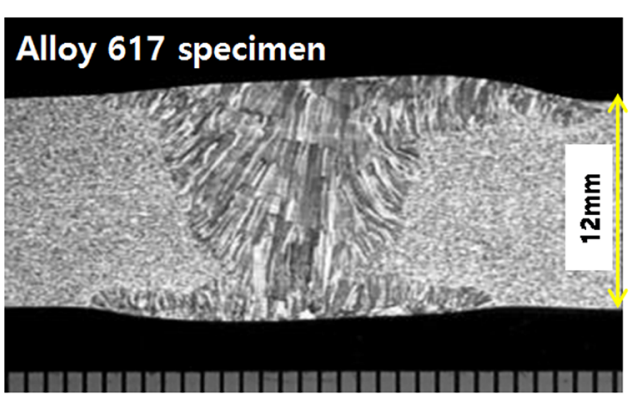

could be confirmed that PWHT resulted in elemental homogenization in the weld metal. And coarse grains and fine particles (indicated as "A") are observed in PWHTed weld metal.

EPMA result for the alloy 617 weld metals is presented in Fig. 8. There are clear segregations of Mo, Ti and Co in the weld metal to occur. Nakkalil et al. [35] explained well the segregation behaviors of solute elements in Ni-based superalloy weld metals using partition coefficient $k$. Co with $k>1$ segregates into the dendrite core, while Mo, Ti and $\mathrm{C}$ with $k<1$ are likely to enrich the interdendritic regions, i.e., the dendrite boundaries, and these elements produce various intermetallic particles. In addition, $k$ values of $\mathrm{Ni}$ and $\mathrm{Cr}$ are approximately to be 1 and they tend to be distributed in a nearly uniform fashion between the dendrite cores and the dendrite boundaries [35, 36]. Thus, the regions where Mo and $\mathrm{Ti}$ segregated are considered to be the dendrite boundaries consisting of $\mathrm{Ti}$ carbides and Ti-Mo carbides. In addition, a faint $\mathrm{C}$ enrichment is observed in the interdendritic regions. On the other hand,

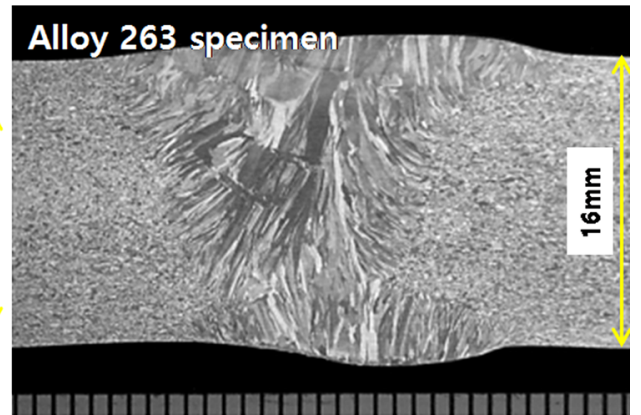

Fig. 5 Macrostructures of as-welded alloy 617 and alloy 263 welds 


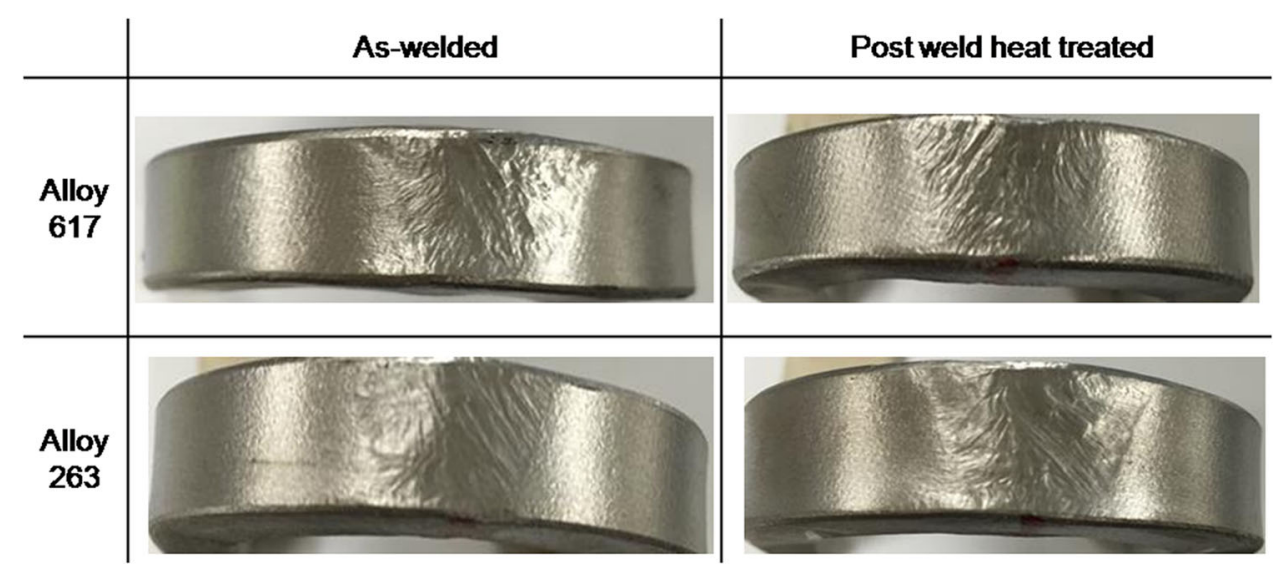

Fig. 6 Specimens after side bending tests
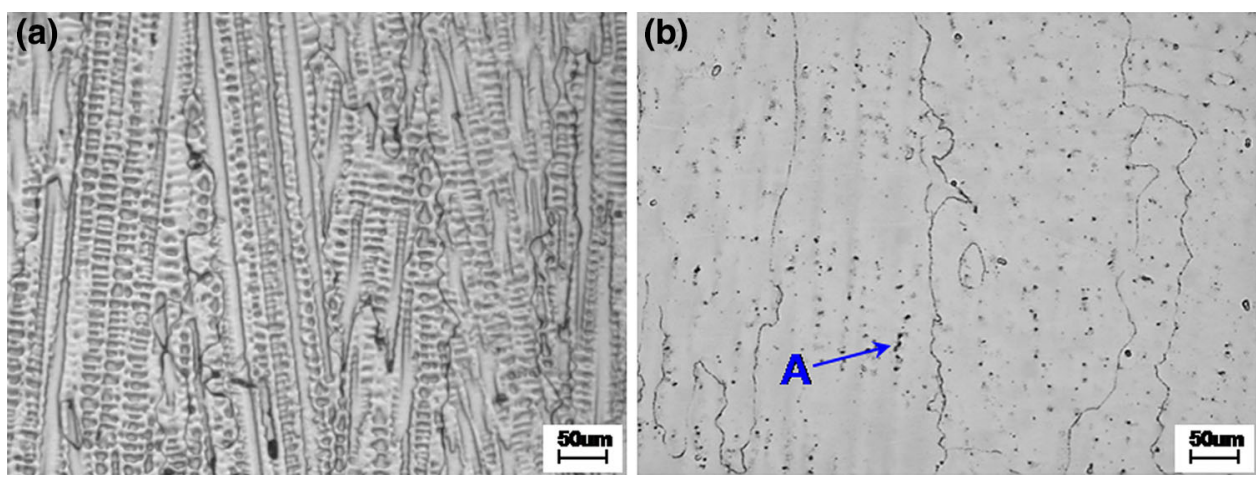

Fig. 7 OM micrographs of alloy 617 weld metals before a, after b PWHT
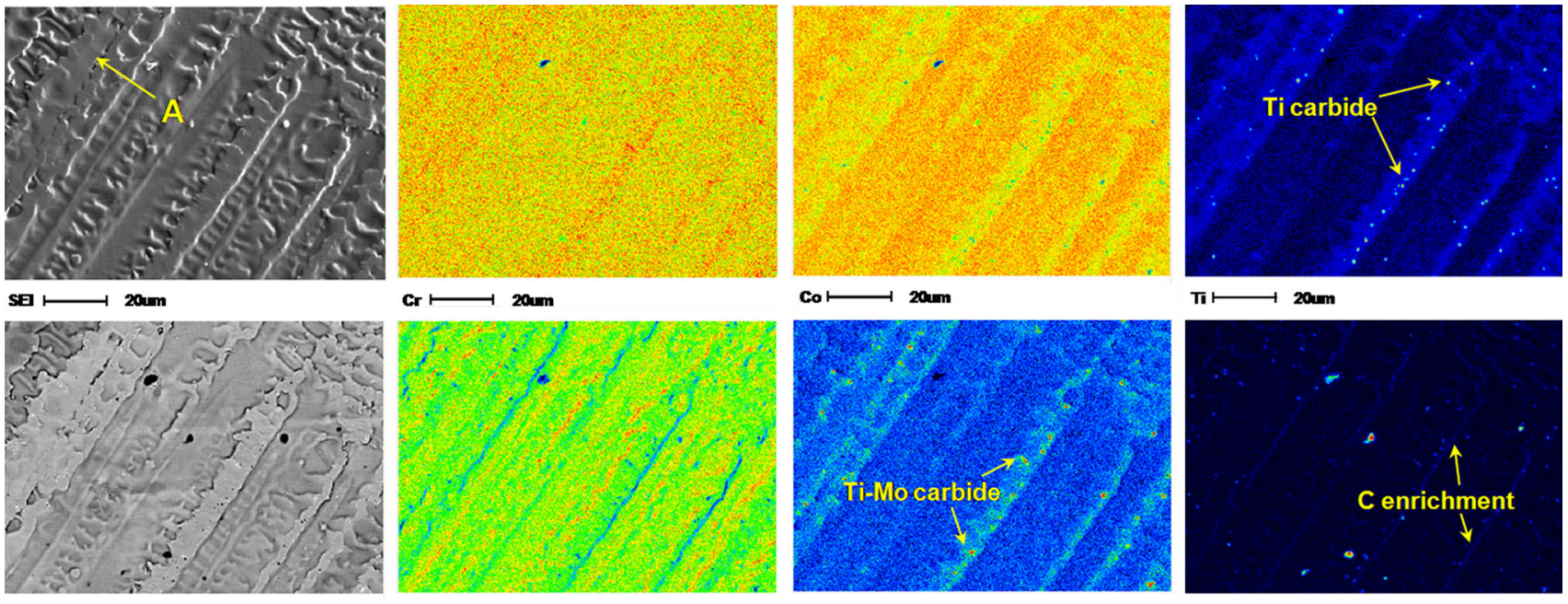

Fig. 8 EPMA of the as-welded alloy 617 weld metal

$\mathrm{Cr}$ and Co did not generate any phases and no phases were observed along the grain boundaries ("A" in Fig. 8) in the as-welded 617 specimen. Although $\mathrm{Cr}$ has stronger affinity with $\mathrm{C}$ than $\mathrm{Mo}$, the $\mathrm{Cr}$ does not form any carbide during solidification [37]. The reason for this is that $\mathrm{Cr}$ may have fewer opportunities to react with C than Mo which segregates into the interdendritic regions.

In EPMA on the 617 weld metal after PWHT (Fig. 9), it is revealed that the $\mathrm{Co}$ and $\mathrm{Mo}, \mathrm{Ti}, \mathrm{C}$ still segregated faintly, although elemental homogenization seemed to 
occur during PWHT through OM observation. The faint segregation of Mo and Ti is mainly observed around the grain boundaries, while that of $\mathrm{Co}$ is in the grains. $\mathrm{Cr}$ segregation that did not appear in the as-welded weld metals is observed around the grain boundaries where Mo and $\mathrm{Ti}, \mathrm{C}$ segregate. The grain boundaries surrounded by the $\mathrm{Mo}, \mathrm{Ti}, \mathrm{Cr}$ and $\mathrm{C}$ segregation are occupied by $\mathrm{Mo}-\mathrm{Cr}-$ Ti carbides, and these carbides are precipitated in the grains as well. Particles of Ti carbides and Mo-Ti carbides are precipitated in the vicinity of the grain boundaries (Fig. 10).

STEM analysis was performed in order to further examine the intergranular $\mathrm{Mo}-\mathrm{Cr}-\mathrm{Ti}$ carbide. Analysis shows the intergranular bulky like $\mathrm{Cr}$ carbides and chainlike Mo-Ti carbides. From these results, it could be inferred that $\mathrm{Mo}, \mathrm{Ti}, \mathrm{Cr}$ and $\mathrm{C}$ segregate into the grain boundaries leading to formation of the carbides during PWHT. Additionally, no particles with Co were observed in the heat-treated specimen. In the alloy 617 weld metals, the significant changes in the microstructures caused by PWHT are thought to be the segregation in the vicinity of the grain boundaries and the precipitation of intergranular carbides is expected to have an effect on mechanical properties of the weld metals. No carbide particles containing Co were detected in either the as-welded or PWHTed 617 weld metals. The reasons for this are thought to be that the affinity of Co with $\mathrm{C}$ is relatively weak in comparison with $\mathrm{Ti}$, Mo and $\mathrm{Cr}$, and that Co is likely to segregate into the dendrite cores and inside the grains before and after PWHT [37].

OM observation and EPMA were also carried out on the microstructure in the weld metals of the $\gamma^{\prime}$ precipitationstrengthened alloy 263, and the results are presented in Fig. 11. The main microstructural difference between the
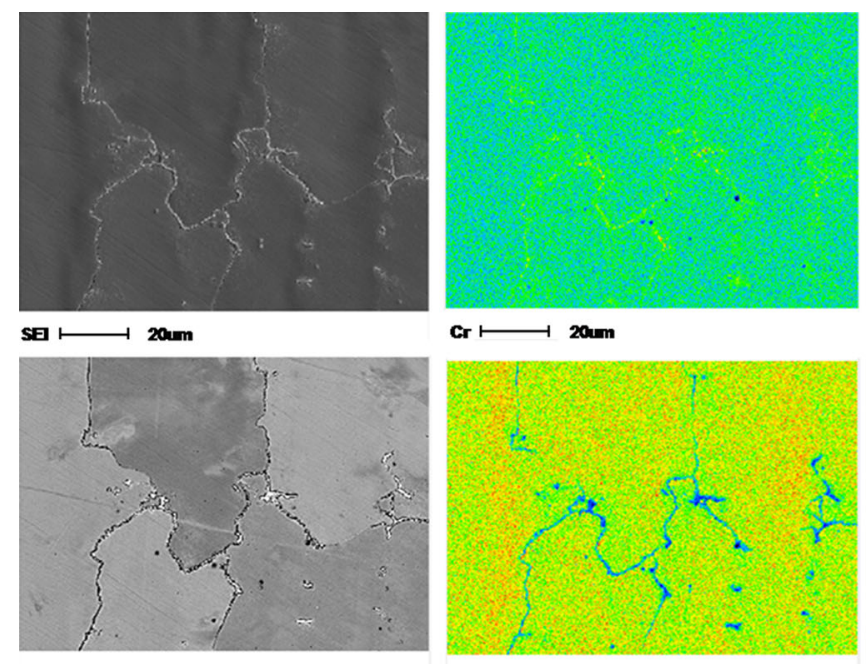

Ni $\longmapsto 20 m$

compo alloy 263 and the alloy 617 is that the dendritic structure is still observed clearly in the alloy 263 weld metal after PWHT. Fine particles appeared in PWHTed 263 weld metal as indicated by "A" in Fig. 11.

Segregations of Co, Mo and Ti are also detected in the as-welded 263 weld metal as shown in Fig. 12. This result shows that the segregation behavior in the alloy 263 weld metal is quite similar to that in the alloy 617 weld metal; in other words, Mo and Ti clump together in the interdendrite boundaries, but $\mathrm{Co}$ in the dendrite cores, and $\mathrm{C}$ segregates faintly into the dendrite boundaries. Two kinds of carbides were thought to be Mo-Ti carbides and Ti carbides. No particles containing $\mathrm{Cr}$ or Co were detected.

EMPA on the alloy 263 weld metal heat-treated at $810{ }^{\circ} \mathrm{C}$ for $4 \mathrm{~h}$ in Fig. 13 indicates that the segregations of $\mathrm{Co}$, Mo and $\mathrm{Ti}$ are still observed and $\mathrm{C}$ segregation appears clearly in the regions where $\mathrm{Mo}$ and $\mathrm{Ti}$ segregation occurred. Co does not form any phases in the heat-treated weld metal. Intergranular $\mathrm{Mo}-\mathrm{Cr}-\mathrm{Ti}$ carbides are also detected in the PWHTed weld metal. Figures 12 and 13 show that the microstructure changes caused by PWHT in the alloy 263 weld metal are quite similar to those in the alloy 617 weld metal. However, the alloy 263 weld metals have several differences in the microstructure from the alloy 617 weld metal and these differences are stated below.

Mo, Ti, C and Co also segregated into the PWHTed alloy 263 weld metal, but the segregation did not have a regional preference for the grains or the grain boundaries. Additionally, no $\mathrm{Cr}$ segregation was observed in the PWHTed alloy 263 weld metal. From EPMA, it could be expected that the grain boundaries would be occupied by the same carbides - the Cr carbides and Mo-Ti carbideswhich precipitated in the PWHTed 617 alloy weld metal.
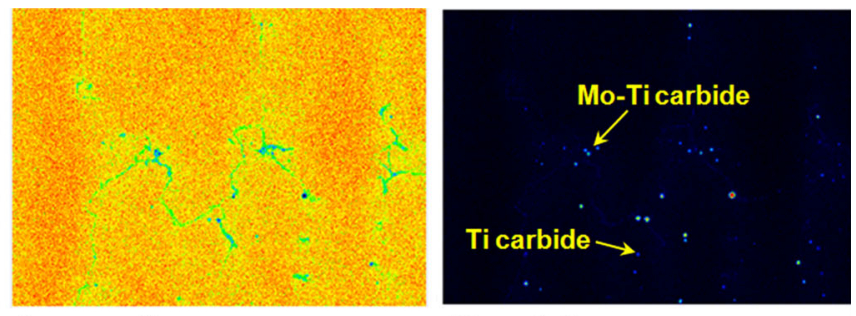
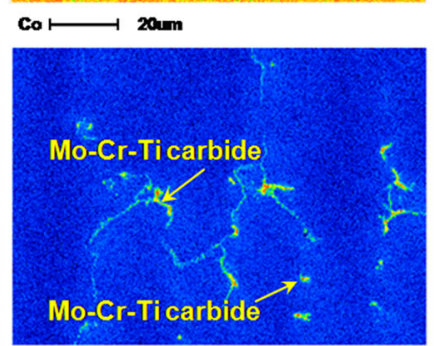
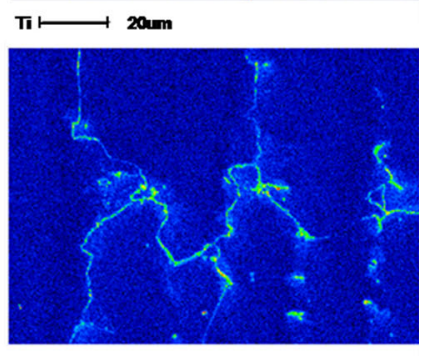

c $200 \mathrm{~m}$

Fig. 9 EPMA of the heat-treated alloy 617 weld metal 

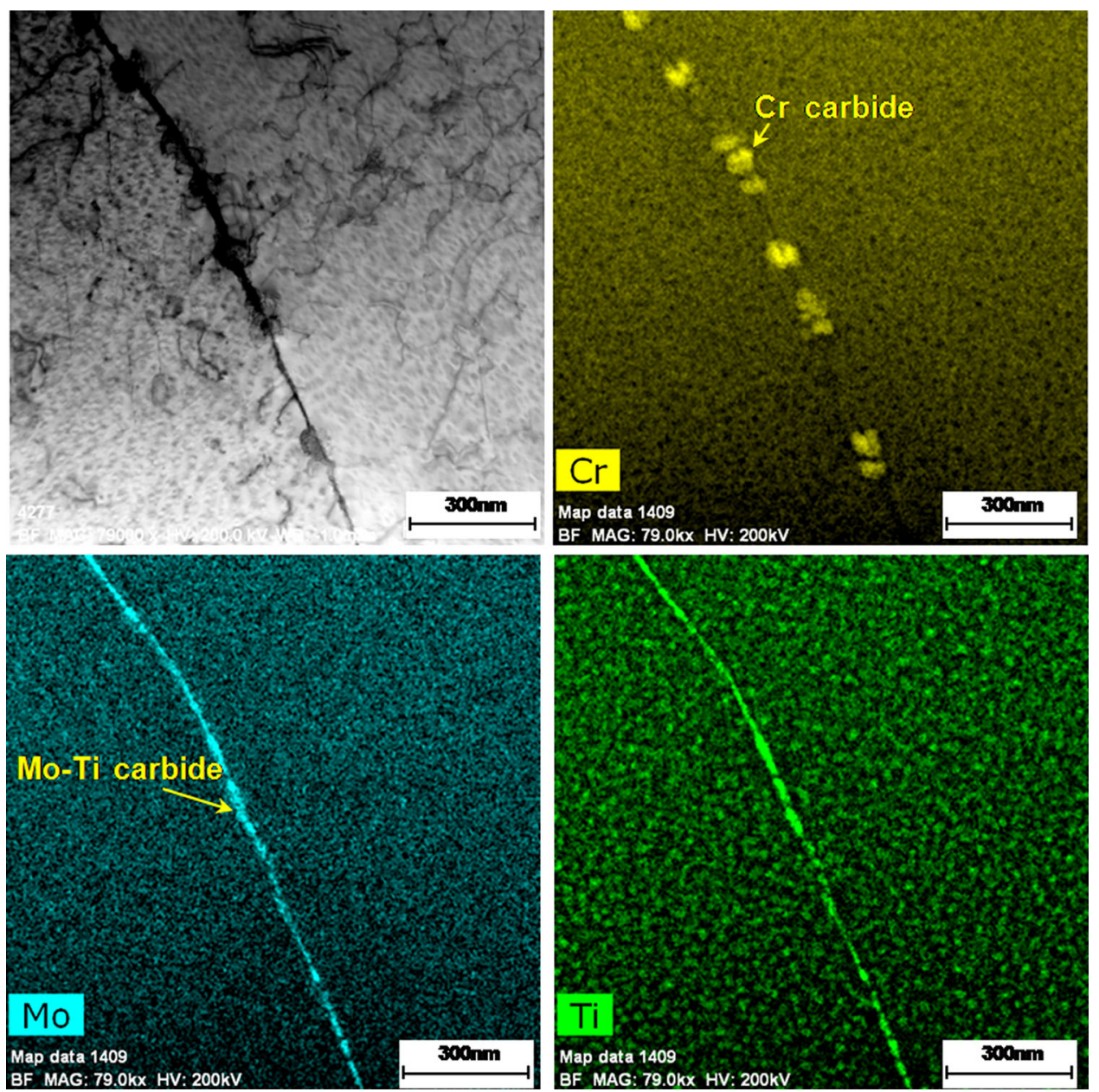

Fig. 10 STEM analysis result on intergranular precipitation in heat-treated alloy 617 weld metal
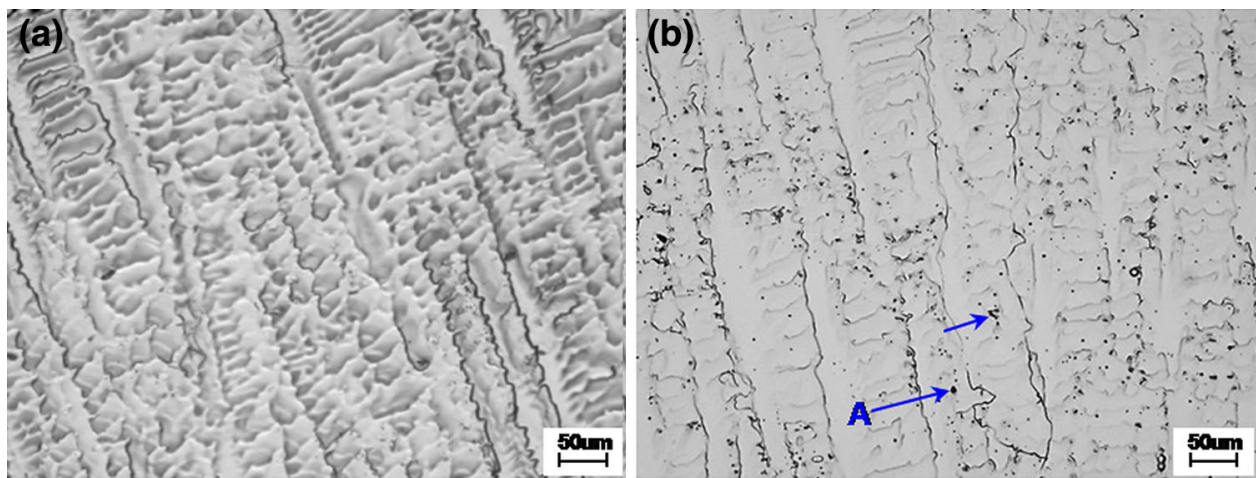

Fig. 11 OM micrographs of alloy 263 weld metals before a, after b PWHT

However, the STEM analysis result on the intergranular carbides in the PWHTed alloy 263 weld metal showed that Cr-Mo carbides and Mo-Ti carbides precipitated along the grain boundary and that $\mathrm{Cr}-\mathrm{Mo}$ carbides were larger than Mo-Ti carbides (Fig. 14). In the PWHTed weld metal of the alloy 617 (Fig. 10), it was confirmed that $\mathrm{Cr}$ carbides precipitated along the grain boundaries. The difference in the intergranular precipitation behavior between alloy 617 and alloy 263 weld metals is understood to be associated with the differences in the chemical composition concentration, particularly Mo and Ti, and in PWHT temperatures for each weld metal.

Although the SEM observation on PWHTed weld metal of the $\gamma^{\prime}$ precipitation-strengthened alloy 263 was performed 


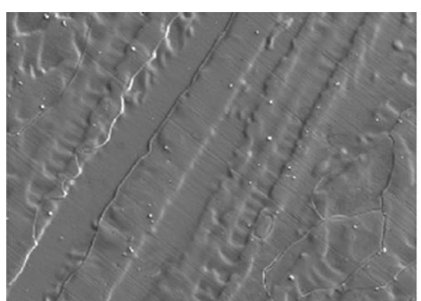

SE

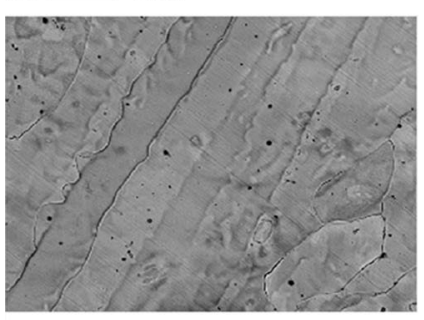

COMPO $\longmapsto 20 u m$

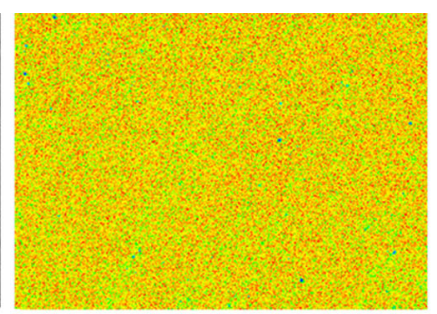

Cr $20 \mathrm{~mm}$

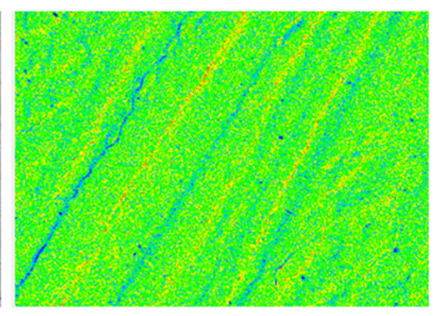

NS

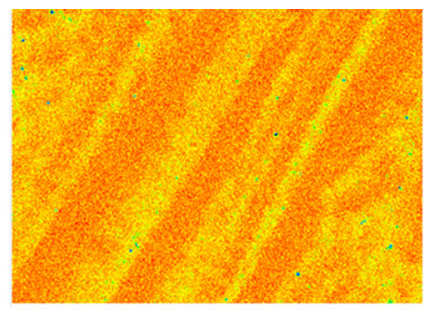

Co $20 \mathrm{~mm}$

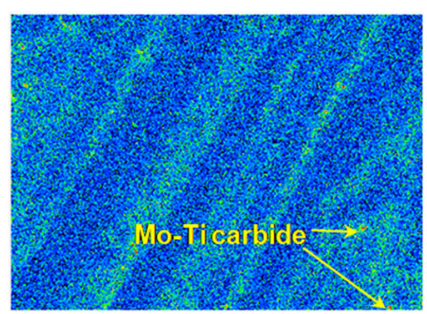

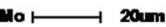

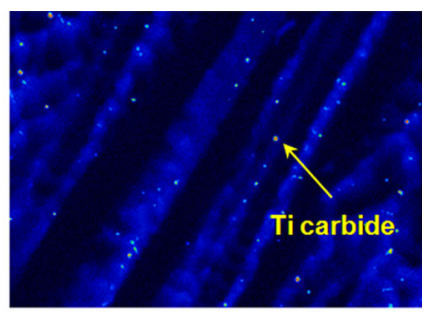

$\pi \longmapsto 200 m$

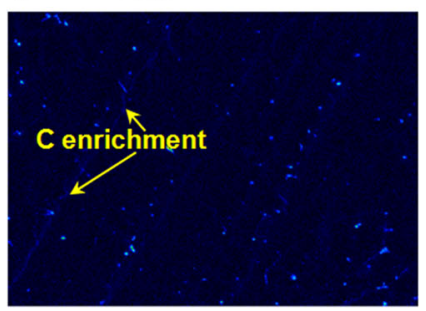

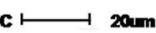

Fig. 12 EPMA analysis result on as-welded alloy 263 weld metal

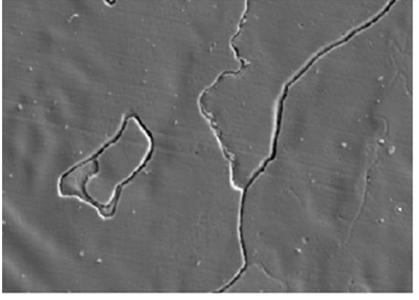

SE

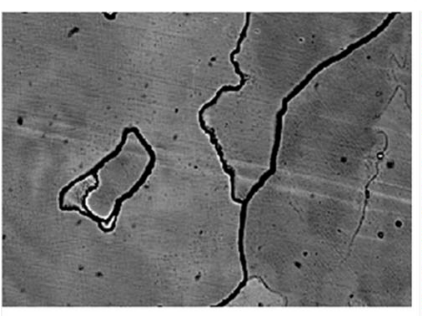

COMPO $\longmapsto 10 \mathrm{~m}$

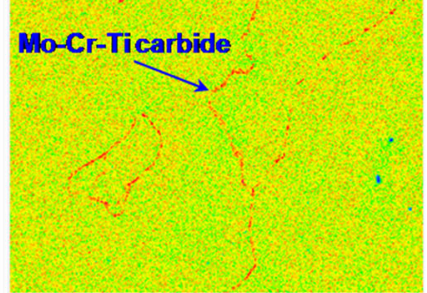

Cr $\longmapsto 10 m$

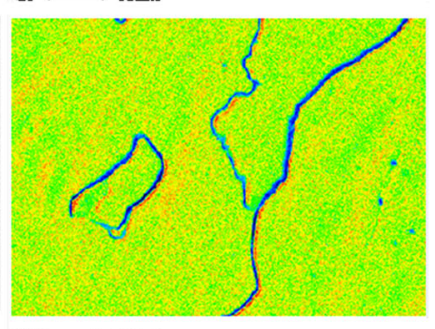

Ni $\longmapsto$ 10um
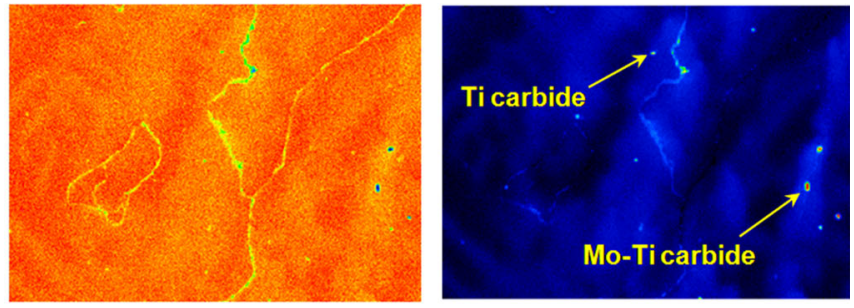

Co $\longmapsto 10 \mathrm{~m}$

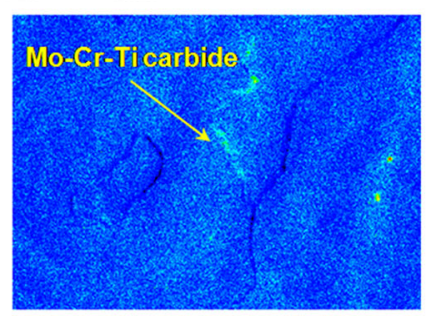

No⺊10m

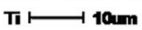

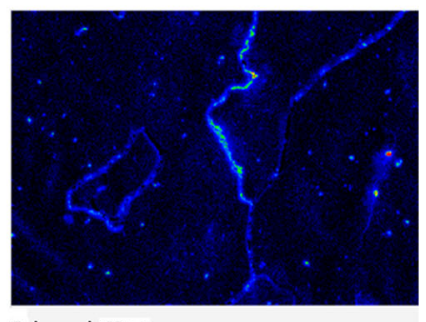

$c \longmapsto 10 \mathrm{~mm}$

Fig. 13 EPMA analysis result on heat-treated alloy 263 weld metal

in high magnification around $\times 10,000, \gamma^{\prime}$ precipitation could not be confirmed, as shown in Fig. 15. It is well known that $\gamma^{\prime}$ precipitates found in alloy 263 are round and very fine particles $<20 \mathrm{~nm}$ in diameter due to relatively low $\mathrm{Ti}$ and $\mathrm{Al}$ concentration, and superalloys with higher $\mathrm{Ti}$ and $\mathrm{Al}$ content such as alloy 738LC for gas turbines have $\gamma^{\prime}$ particles about $1 \mu \mathrm{m}$ in diameter $[9,38]$. Therefore, $\gamma^{\prime}$ particles in the alloy 263 could be thought to be too fine to detect with SEM.

For further examination on the precipitation of $\gamma^{\prime}$ particles, STEM characterization was carried out with the heat-treated 263 weld metal, and the STEM analysis result is presented in Fig. 16. A bright field image (BF) shows a number of fine round particles about $10 \mathrm{~nm}$ in diameter. EDS elemental mapping on $\mathrm{Ni}, \mathrm{Ti}$ and $\mathrm{Al}$ clarified that the particles were $\gamma^{\prime}$ precipitates of $\mathrm{Ni}_{3} \mathrm{Al}(\mathrm{Ti})$. With this analysis, it could be concluded that fine $\gamma^{\prime}$ particles were precipitated during PWHT and $\mathrm{Al}$ was also involved in the formation of $\gamma^{\prime}$ in spite of its low concentration of about $0.4 \mathrm{wt} \%$.

Figure 17 shows the tensile strength of the 617 and 263 weld specimens. All the specimens fractured at the weld metal. For the alloy 617, the strength increases about $100 \mathrm{MPa}$ after PWHT, while for alloy 263 about $250 \mathrm{MPa}$, fracturing at over $1000 \mathrm{MPa}$. The tensile strength of PWHTed alloy 263 weld metal in the present work is slightly higher than that reported in the previous study [28]. The authors of this study believed that the drastic increase in the tensile strength of the alloy 263 after PWHT was induced by not only $\gamma^{\prime}$ precipitation but also other microstructural changes such as intergranular carbides and 

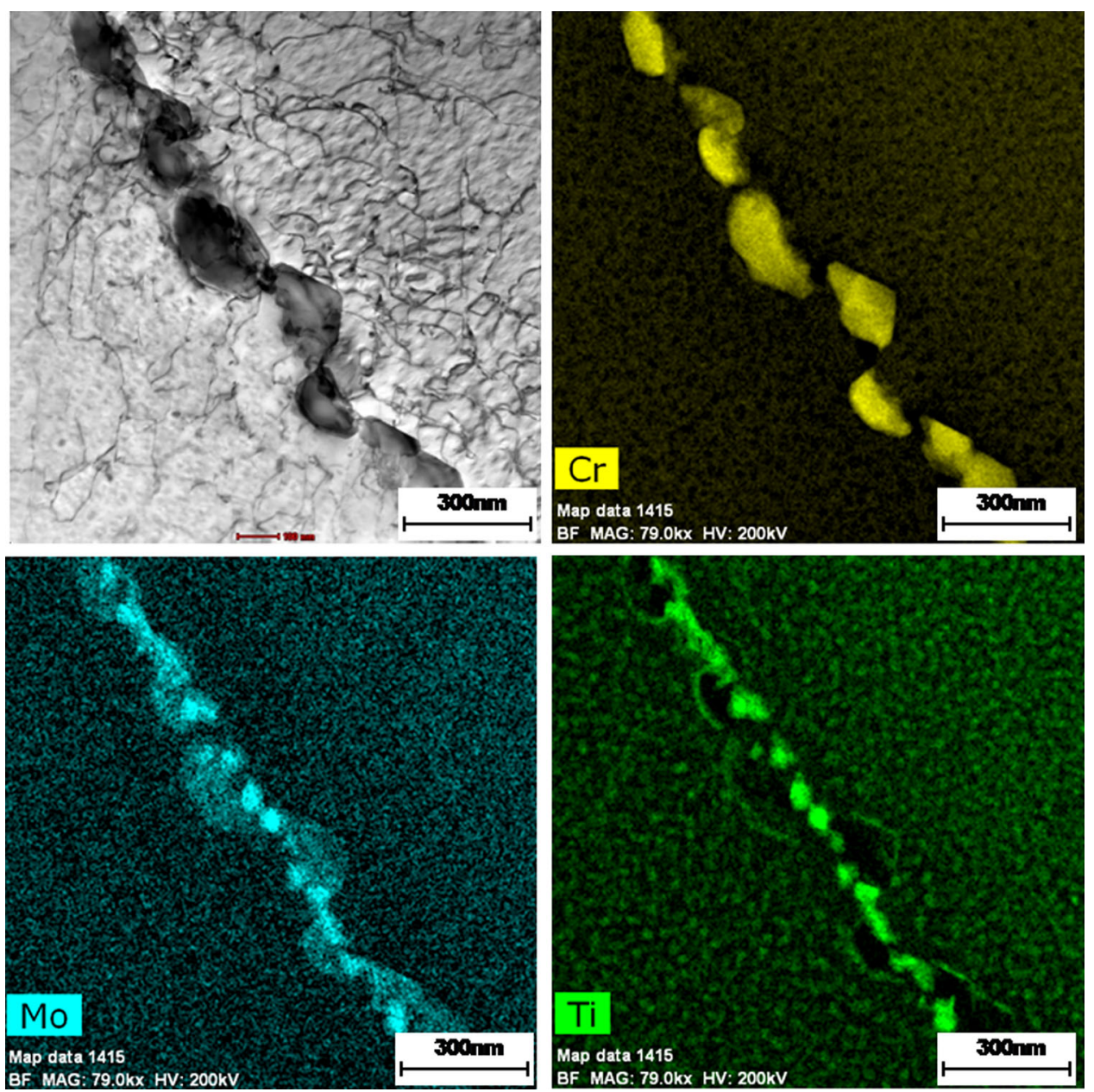

Fig. 14 STEM analysis result on intergranular precipitation in heat-treated alloy 263 weld metal

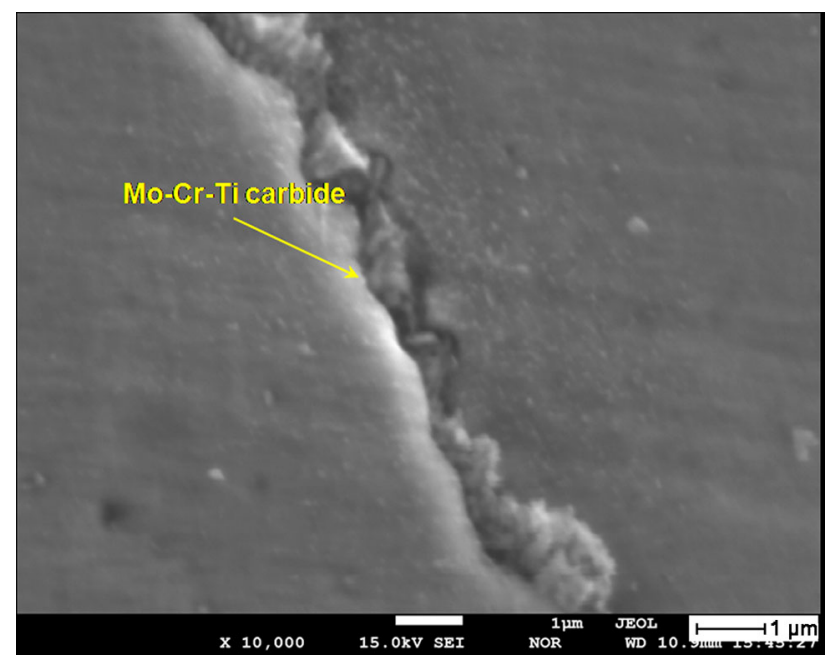

Fig. 15 High-magnification SEM image around the grain boundary of heat-treated alloy 263 weld metal

elemental segregation. Nonetheless, the main cause for the increase in tensile strength of the alloy 263 after PWHT was thought to be $\gamma^{\prime}$ precipitation, because the alloy 617 had relatively small strength increase despite the microstructural changes induced by PWHT in the alloy 617 weld metal being similar to those of the alloy 263 weld metal, with the exception of $\gamma^{\prime}$ precipitation.

On the other hand, some researchers reported that the precipitation of $\gamma^{\prime}$ occurred in alloy 617, defined as solid solution-strengthened superalloy, because the alloy contained more than $1 \mathrm{wt} \% \mathrm{Al}$, one of the $\gamma^{\prime}$ precipitating elements, and that this might result in deterioration of the properties of the alloy [1]. However, the tensile test result in this article demonstrated clearly that $\gamma^{\prime}$ precipitation did not occur in the alloy 617 weld metals during PWHT, although further experiments to confirm whether $\gamma^{\prime}$ was precipitated in the weld metal were not carried out. $\gamma^{\prime}$ precipitation temperatures of alloy 617 and alloy 263 were calculated by the JmatPro simulation program, and Fig. 18 shows the calculation results. $\gamma^{\prime}$ precipitation is expected not only in alloy 263 but also in alloy 617, and the starting temperatures for the precipitation in both alloys are around $800{ }^{\circ} \mathrm{C}$ in the calculation result. From the results, it could be concluded that the PWHT temperature of $980{ }^{\circ} \mathrm{C}$ 

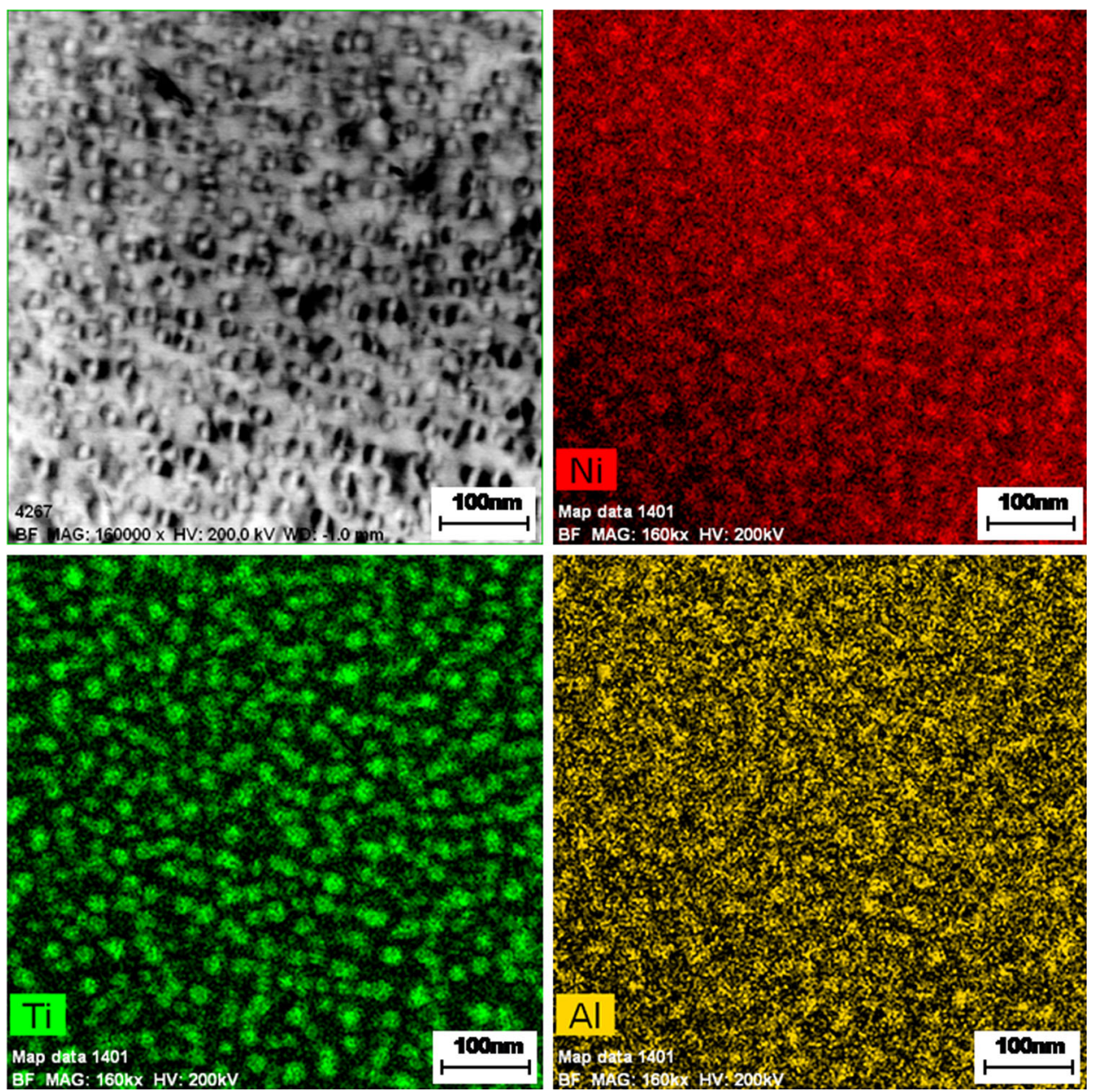

Fig. 16 STEM analysis result on heat-treated alloy 263 weld metal

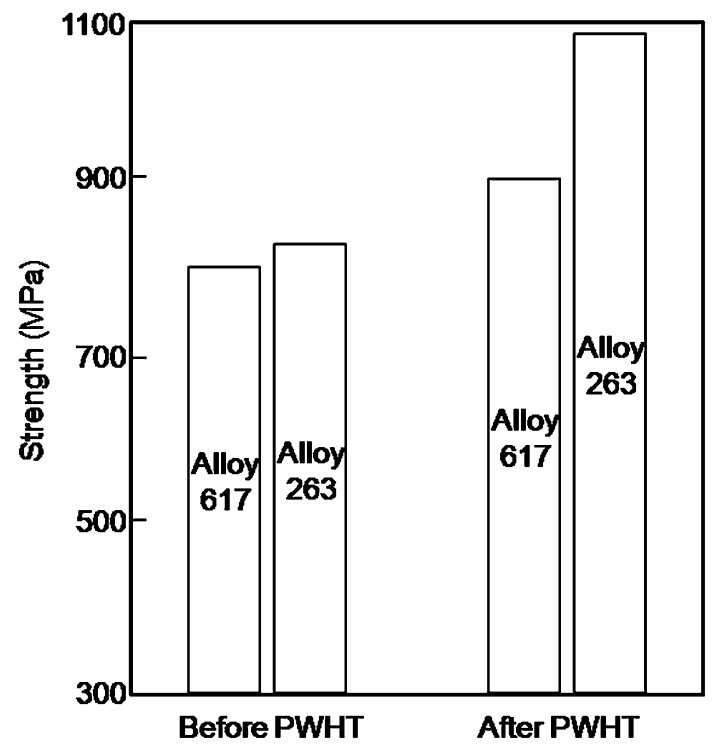

Fig. 17 Tensile strength of alloy 617 and alloy 263 welds before and after PWHT

suggested by the welding consumable manufacturer was too high to precipitate $\gamma^{\prime}$ particles and $\gamma^{\prime}$ precipitation did not develop due to the fast cooling rate after PWHT finished.

Based on the experimental results on the alloy 617 and alloy 263 weld metals as stated above, it is found consequently that these superalloy weld metals have meaningful microstructure through PWHT, and it has a decisive influence on the mechanical properties of the weld metals, and also that $\gamma^{\prime}$ precipitation plays an important role in improving the mechanical properties of alloy 263 weld metals after PWHT.

However, precipitation and deterioration of $\gamma^{\prime}$ as well as other phases such as carbides and their effects on properties of the weld metals according to various PWHT conditions need to be studied to utilize these candidate materials for HSC plants. Further investigations on these behaviors will be performed in a future study. 

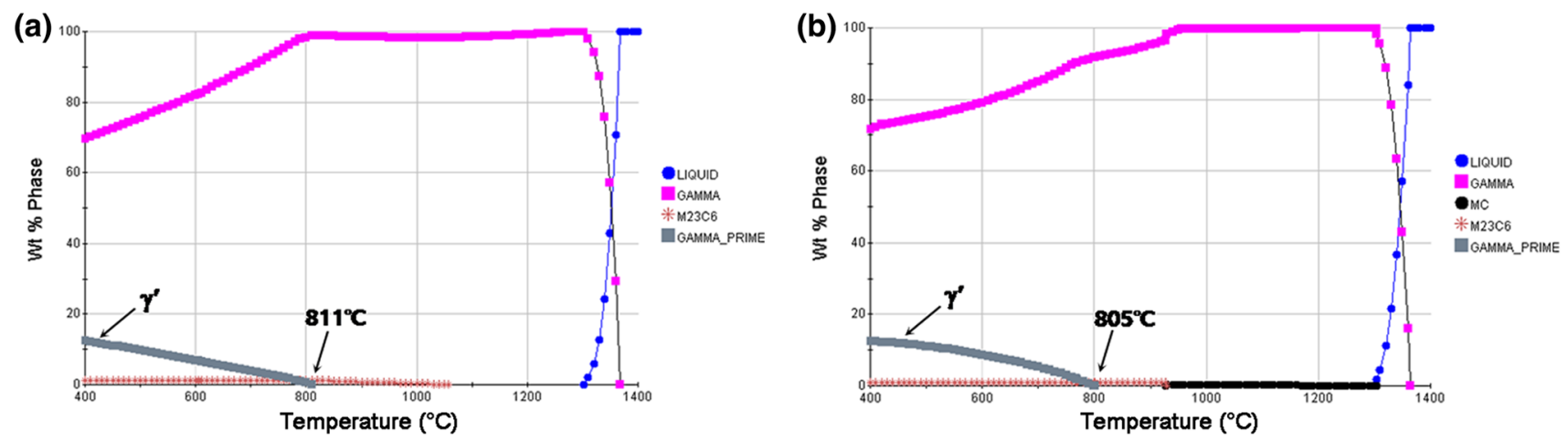

Fig. 18 Calculated $\gamma^{\prime}$ precipitation temperatures of alloy 617 a, alloy $263 \mathbf{b}$ by JmatPro

\section{Conclusion}

In this article, the effect of PWHT on the microstructure and the mechanical properties of alloy 617 and alloy 263 weld metals was examined carefully. The following conclusions could be drawn:

1. Both of the superalloys and welding consumables showed a good weldability in penetration inspection. No cracking occurred in any of the bending-tested specimens before or after PWHT.

2. Segregations of $\mathrm{Co}, \mathrm{C}, \mathrm{Mo}$ and Ti were observed in the as-welded weld metal in the as-welded 617 weld metal. The enrichments of $\mathrm{Co}$, Mo and $\mathrm{Ti}$ were detected faintly, and $\mathrm{Cr}$ segregation was identified after PWHT. No precipitation of Co was detected in the as-welded or PWHTed 617 weld metals. The grain boundaries surrounded by the $\mathrm{Mo}, \mathrm{Cr}$ and $\mathrm{C}$ segregation were occupied by bulky $\mathrm{Cr}$ carbides and linear Mo-Ti carbide in the heat-treated specimen.

3. The as-welded 263 weld metal also showed the segregations of $\mathrm{Co}, \mathrm{C}, \mathrm{Mo}$ and Ti. In PWHTed weld metal, the segregation was still clearly observed. Intergranular precipitation in PWHTed 263 weld metal consisted of $\mathrm{Cr}-\mathrm{Mo}$ carbides and Mo-Ti carbides. STEM analysis results on alloy 263 weld metal that had undergone PWHT at $810{ }^{\circ} \mathrm{C}$ for $4 \mathrm{~h}$ clarified that $\gamma^{\prime}$ particles about $10 \mathrm{~nm}$ in size were formed during PWHT and that Al was involved in the precipitation despite its low concentration.

4. In the tensile test, the tensile strength of the alloy 263 weld metal increased sharply to more than $1000 \mathrm{MPa}$ after PWHT, and this resulted mostly from $\gamma^{\prime}$ precipitation.

Acknowledgments This work was supported by the Korea Evaluation Institute of Industrial Technology Grant funded by the Korean government (No. 2015-10052860).

\section{References}

[1] S.F. DiMartino, R.G. Faulkner, S.C. Hogg, S. Vujic, O. Tassa, Mater. Sci. Eng. A 619, 77 (2014)

[2] H.J. Jang, S.Y. Kang, J.J. Lee, T.S. Kim, S.J. Park, Appl. Therm. Eng. 87, 352 (2015)

[3] S.H. Hong, G.S. Kim, J. Weld. Join. 16, 1 (1998)

[4] K. Maile, Pro. Eng. 55, 214 (2013)

[5] J.S. Ahn, J.K. Park, G.J. Lee, J.Y. Yoon, J. Weld. Join. 33, 30 (2015)

[6] G.S. Brzozowska, D.M. Florez, J. Maier, G. Scheffknecht, Fuel 108, 521 (2013)

[7] F. Liu, M. Rashidi, L. Johansson, J. Hald, H.O. Andrén, Scr. Mater. 113, 93 (2016)

[8] T. Jiang, L. Chen, F. Jiang, H. Cai, J. Sun, Mater. Sci. Eng. A 656, 184 (2016)

[9] R.C. Reed, The Superalloys (Cambridge University Press, Cambridge, 2006), p. 58

[10] M.H. Haafkens, J.H.G. Matty, Weld. J. 61, 11 (1982)

[11] X. Xing, X. Di, B. Wang, J. Alloys Compd. 593, 110 (2014)

[12] T.J. Kelly, Weld. J. 2, 44 (1989)

[13] O.A. Ojo, N.L. Richards, M.C. Chaturvedi, Scr. Mater. 51, 683 (2004)

[14] L.O. Osoba, R.G. Ding, O.A. Ojo, Mater. Charact. 65, 93 (2012)

[15] H.A. Chu, M.C. Young, H.C. Chu, L.W. Tsay, C. Chen, J. Nucl. Mater. 433, 419 (2013)

[16] Y. Mei, Y. Liu, C. Liu, C. Li, L. Yu, Q. Guo, H. Li, Mater. Des. 89, 964 (2016)

[17] S.L. Jeng, H.T. Lee, T.Y. Kuo, K.C. Tsai, C.L. Chung, J.Y. Huang, Mater. Des. 87, 920 (2015)

[18] M. Prager, C.S. Shira, Weld. Res. Counc. Bull. 128, 1 (1968)

[19] O.A. Ojo, N.L. Richards, M.C. Chaturvedi, Scr. Mater. 51, 141 (2004)

[20] O.A. Idowu, O.A. Ojo, M.C. Chaturvedi, Mater. Sci. Eng. A 454-455, 389 (2007)

[21] K.D. Ramkumar, R.J. Sai, G. Sridhar, V.S. Reddy, P. Prabaharan, N. Arivazhagan, N. Sivashanmugham, Acta Metall. Sin. (Engl. Lett.) 28, 196 (2015)

[22] M. Preuss, P.J. Withers, G.J. Baxter, Mater. Sci. Eng. A 437, 38 (2006)

[23] I.S. Woo, K. Nishimoto, Met. Mater. Int. 7, 241 (2001)

[24] M. Manikandan, N. Arivazhagan, M. Nageswara, G.M. Reddy, Acta Metall. Sin. (Engl. Lett.) 28, 208 (2015)

[25] H. Shah Hosseini, M. Shamanian, A. Kermanpur, Mater. Charact. 62, 425 (2011)

[26] W. Liu, F. Lu, R. Yang, X. Tang, H. Cui, J. Mater. Process. Technol. 225, 221 (2015) 
[27] G.V.S. Murthy, S. Ghosh, M. Das, G. Das, R.N. Ghosh, Mater. Sci. Eng. A 488, 398 (2008)

[28] P.N. Singh, V. Singh, Scr. Mater. 34, 1861 (1996)

[29] W.Z. Wang, H.U. Hong, I.S. Kim, B.G. Choi, H.W. Jeong, M.Y. Kim, C.Y. Jo, Mater. Sci. Eng. A 523, 242 (2009)

[30] G. Maier, O. Hubsch, H. Riedel, C. Somsen, J. Klower, R. Mohrmann, Cyclic plasticity and lifetime of the nickel-based alloy C-263: experiments, models and component simulation, in MATEC Web Conference, vol. 14, (2014), p. 16006

[31] N.H. Heo, H.S. Shin, S.J. Kim, Met. Mater. Int. 20, 129 (2014)

[32] D.J. Lee, Y.S. Kim, Y.T. Shin, E.C. Jeon, S.H. Lee, H.J. Lee, S.K. Lee, J.H. Lee, H.W. Lee, Met. Mater. Int. 16, 813 (2010)

[33] M. Cloots, K. Kunze, P.J. Uggowitzer, K. Wegener, Mater. Sci. Eng. A 658, 68 (2008)
[34] Y. Long, P. Nie, Z. Li, J. Huang, X. Li, X. Xu, Trans. Nonferr. Met. Soc. China 26, 431 (2016)

[35] R. Nakkalil, N.L. Richards, M.C. Chaturvedi, Scr. Mater. 26, 545 (1992)

[36] S.A. David, J.M. Vitek, S.S. Babu, L.A. Boatner, R.W. Reed, Sci. Technol. Weld. Join. 2, 79 (1997)

[37] The Japan Institute of Metals and Materials, Metal data book, 4th edn. (Maruzen, 2010), p. 109

[38] C. Crozet, A. Devaux, D. Bechet, Microstructure stability: optimization of 263 Ni-based superalloy, in Eurosuperalloy, MATEC Web Conference, vol. 14, (2014), p. 17006 